\title{
A apropriação conservadora do ciclo de protestos de 2013: rumo aos protestos anti-Dilma?
}

\author{
Marcelo Kunrath Silva \\ Professor Titular do Departamento de Sociologia/UfRGS \\ mksilva@ufrgs.br
}

\section{Resumo}

O artigo analisa o ciclo de protestos de 2013 no Brasil, a partir de três questões: Como caracterizar este ciclo de protesto? Quais foram seus principais atores? Como foram produzidas as mudanças qualitativas observadas entre as diferentes fases do ciclo de protestos? O argumento central é que a ação contenciosa de movimentos sociais progressistas, que caracterizou a primeira fase do ciclo, foi identificada e interpretada por contramovimentos conservadores como uma oportunidade para sua própria mobilização. Esta apropriação parcial do ciclo de protestos pelos contramovimentos seria o mecanismo que produz a mudança qualitativa observada na segunda fase do ciclo. Neste processo de apropriação foram gestados e/ou fortalecidos atores, redes e recursos que tiveram centralidade na construção das mobilizações anti-Dilma em 2015 e 2016.

\section{Palavras-chave}

Ciclo de Protestos - 2013 - Movimentos Sociais - Contramovimentos Conservadorismo 


\title{
The Conservative Appropriation of the 2013 Cycle of Protest: Towards Anti-Dilma Protests?
}

\begin{abstract}
The article analyzes the cycle of protests of 2013 in Brazil in order to answer three questions: How to characterize this cycle of protest? Who were your main actors? How were the qualitative changes observed between the different phases of the protest cycle produced? The main argument is that the contentious action of progressive social movements, which characterized the first phase of the cycle, was identified and interpreted by conservative countermovements as an opportunity for its own mobilization. This partial appropriation of the cycle of protests by the countermovements would be the mechanism that produces the qualitative change observed in the second phase of the cycle. In this process of appropriation were created and/or strengthened actors, networks and resources that had centrality in the construction of the anti-Dilma mobilizations in 2015 and 2016.
\end{abstract}

\section{Keywords}

Cycle of Protest - 2013 - Social Movements - Countermovements - Conservatism

\section{L'appropriation conservatrice du cycle de manifestations de 2013 : vers des manifestations anti-Dilma?}

\section{Résumé}

Cet article analyse le cycle des manifestations de 2013 au Brésil, à partir de trois questions : Comment caractériser ce cycle de manifestations? Qui étaient ses acteurs principaux? Comment les changements qualitatifs observés entre les différentes phases du cycle de manifestations ont-ils été produits? L'argument central est que l'action de protestation des mouvements sociaux progressistes, qui ont caractérisé la première phase du cycle, a été identifiée et interprétée par des contre-mouvements conservateurs comme une opportunité pour sa propre mobilisation. Cette appropriation partielle du cycle de manifestations de la part des contre-mouvements serait le mécanisme qui produit le changement qualitatif observé dans la deuxième phase du cycle. Dans ce processus d'appropriation, des acteurs, des réseaux et des ressources ont été 
créés et / ou renforcés, lesquels ont joué un rôle central dans la construction de mobilisations anti-Dilma en 2015 et 2016.

\section{Mots-Clés}

Cycle des Manifestations - 2013 - Mouvements Sociaux - Contre-Mouvements Conservatisme

\section{Introdução}

Na noite de 20 de junho de $2013^{1}$, ápice do ciclo de protestos de 2013 no Brasil, Porto Alegre tem mais uma manifestação agendada. Apesar da redução da tarifa de ônibus ter ocorrido no final de abril, os protestos continuam a ocorrer na cidade quase que semanalmente durante o mês de junho. Desde o final da tarde, manifestantes começam a se reunir em frente à Prefeitura. $\mathrm{O}$ número de manifestantes aumentou significativamente desde o início de junho e as estimativas variam de 20 a 30 mil pessoas reunidas nesta noite. O público é muito distinto daquele que compunha as manifestações contra o aumento da passagem. Observam-se alguns conflitos relacionados à presença de bandeiras de partidos de esquerda, que são objeto de vaias de indivíduos que portam símbolos nacionais ou regionais. Enquanto alguns grupos entoam cânticos anticapitalistas, outros grupos cantam o hino nacional e o hino do estado do Rio Grande do Sul. Há uma grande quantidade de cartazes confeccionados por indivíduos defendendo as causas mais diversas. Ao mesmo tempo, podem ser observados muitos cartazes iguais, com uma lista de cinco causas (todas relacionadas à corrupção) que deveriam ser defendidas pelos manifestantes ${ }^{2}$. Militantes de organizações articuladas no Bloco de Lutas tentam dirigir o protesto, mas a todo momento ocorrem conflitos em relação ao trajeto, às palavras de ordem, aos repertórios de ação, entre outros. Conflitos também irrompem entre manifestantes que utilizam táticas violentas e manifestantes contrários ao uso destas táticas. Gritos de "Sem violência" são respondidos com gritos de

1 Descrição feita a partir de registros de observações nos atos de protesto de 2013 em Porto Alegre.

2 Alguns dias depois, uma reportagem em jornal local informava que a impressão e distribuição de milhares de cartazes com as “ 5 causas" foram pagas por alguns empresários. 
"Violenta é a polícia". Dependendo da localização na manifestação, o observador poderia caracterizá-la como uma manifestação da esquerda partidária, de coletivos anarquistas ou de grupos nacionalistas e conservadores. Ao mesmo tempo, diversos grupos de jovens da periferia se deslocam ao lado da manifestação, esperando a oportunidade para realizar saques em estabelecimentos comerciais.

Na noite de 27 de junho de 2013, o Bloco de Lutas decide modificar a forma de manifestação: ao invés de uma caminhada, um ato político-cultural na Praça da Matriz, em frente à sede do governo do estado do Rio Grande do Sul. $\mathrm{O}$ ambiente é de tensão. De um lado, forças policiais posicionadas para proteger diversos prédios públicos existentes no local ficam frente a frente com os manifestantes. De outro lado, parte dos manifestantes rejeita o ato político-cultural entoando a palavra de ordem "protesto não é festa". Além disto, grupos de jovens de periferia que fizeram saques em atos anteriores estão inquietos pela impossibilidade de novos saques em um local sem comércio, altamente policiado e em um ato sem deslocamento. Neste cenário conflitivo, um helicóptero sobrevoa a manifestação durante vários minutos e, através de um letreiro luminoso, começa a transmitir mensagens contra a corrupção, em defesa da atuação policial, de apoio à manifestação mas não à violência, entre outras. Após um tempo, manifestantes contrários ao ato políticocultural derrubam cercas de proteção e o confronto com a polícia irrompe na Praça.

O ciclo de protestos de 2013 produziu um abalo profundo não apenas na sociedade brasileira, mas também nas interpretações acadêmicas sobre a mesma. A conflitualidade que emerge neste/deste processo, com diversas inovações em termos de forma, conteúdo e atores promotores, confrontou quadros interpretativos predominantes até aquele momento. Abordagens que tomavam a institucionalização dos movimentos e conflitos sociais e o abandono de repertórios de confronto como características da democracia brasileira, especialmente após a chegada do Partido dos Trabalhadores (PT) à presidência da República em 2003, tiveram que ser revistas. A própria ideia de consolidação da democracia passou a ser problematizada.

A complexidade e as novidades deste ciclo de protestos, que a rápida descrição de alguns episódios observados em Porto Alegre apresentada acima exemplifica, ainda hoje colocam-se como desafios para sua análise. Observam-se na literatura discordâncias profundas no que se refere à própria caracterização 
empírica do processo. Neste sentido, duas questões que orientam a análise desenvolvida no presente artigo têm um caráter descritivo: Como caracterizar o ciclo de protesto de 2013? Quais foram seus principais atores?

Nesta caracterização, destaca-se a ocorrência de transformações importantes ao longo do ciclo de protestos. Apesar de relacionadas por comporem o mesmo ciclo de protesto, as primeiras manifestações ocorridas nos meses de abril e maio, diretamente vinculadas ao aumento da passagem do transporte público, apresentam poucas similaridades com as massivas manifestações que se difundem pelo país em meados de junho. A busca pela compreensão de tais transformações se expressa na terceira questão a ser respondida pelo artigo: Como foram produzidas as mudanças qualitativas observadas entre as diferentes fases do ciclo de protestos de 2013?

Assim, o objetivo do presente artigo é contribuir na resposta a estas questões, que estão no centro do debate científico (e político) brasileiro. A fundamentação empírica da análise é constituída por pesquisas produzidas no âmbito do Grupo de Pesquisa Associativismo, Contestação e Engajamento da Universidade Federal do Rio Grande do Sul (GPACE - www.ufrgs.br/gpace/) observações e entrevistas realizadas pelo autor durante o ciclo de protestos de 2013 na cidade de Porto Alegre, assim como pesquisas feitas por outros investigadores. Destaca-se, no entanto, que a análise não é fruto de uma pesquisa sistemática sobre o processo nacional. Desta forma, propõe-se um quadro interpretativo geral construído a partir dos referenciais teóricos mobilizados e de informações acessadas ou produzidas pelo autor, o qual pode apresentar diferenças mais ou menos significativas em relação a processos locais.

O argumento central do artigo é que a ação contenciosa de movimentos sociais progressistas, que caracterizou a primeira fase do ciclo de protestos de 2013, é identificada e interpretada por contramovimentos conservadores como uma oportunidade para sua própria mobilização ${ }^{4}$. A mobilização destes

3 Os resultados de tais pesquisas encontram-se em Fernandes (2016) e Silva (2016).

4 Devido à diversidade de atores que atuam no ciclo de protestos de 2013, conforme exemplificam os relatos iniciais, uma das dificuldades da análise refere-se à categorização de tais atores. Alonso e Mische (2016), utilizando como critério de categorização os repertórios utilizados, identificam dois campos de ação estratégica atuando no ciclo de protestos de 2013: o patriótico e o autonomista. Adota-se aqui uma categorização a partir das causas defendidas, diferenciando entre: "progressistas" (atores que apoiam/defendem causas de segmentos subalternizados da sociedade brasileira que confrontam relações de desigualdade) e "conservadores" (atores que apoiam/defendem causas de segmentos dominantes da sociedade brasileira que reproduzem relações de desigualdade). Sabe-se, no entanto, que a classificação 
contramovimentos e, especialmente, a sua capacidade de apropriação parcial do ciclo de confronto é o processo que produz a mudança qualitativa observada na segunda fase do ciclo de protestos de 2013. A convergência improvável e conflitiva destes movimentos e contramovimentos nas manifestações de junho de 2013 foi temporariamente possível por dois fatores: o compartilhamento de posicionamentos críticos (mesmo que por motivos distintos) aos governos do PT e à política institucional e/ou ao Estado.

Para apresentar e sustentar esta argumentação, o artigo encontra-se estruturado da seguinte forma: a próxima seção apresenta, de forma breve, os referenciais teóricos que orientam a análise realizada; a seção terceira justifica o uso do conceito "ciclo de protestos" para abordar o processo contencioso ocorrido em 2013; a quarta seção faz uma caracterização sucinta das três fases do ciclo de protestos de 2013, demonstrando a ocorrência de importantes mudanças qualitativas entre estas fases; a quinta seção analisa como estas mudanças qualitativas estão relacionadas à atuação de contramovimentos conservadores que se apropriam, parcial e temporariamente, dos protestos; a sexta seção aborda as condições que possibilitaram o improvável compartilhamento das ruas por atores progressistas e conservadores na segunda fase do ciclo de protestos de 2013; por fim, as conclusões sintetizam os principais resultados da análise realizada nas seções precedentes.

Mas uma questão ainda precisa ser respondida nessa introdução: Por que a compreensão do ciclo de protestos de 2013 é importante para a análise do processo de destituição da presidenta Dilma Rousseff em 2016, tema do presente dossiê? Mesmo que não se possa estabelecer uma relação causal direta entre estes dois processos e se deva evitar o equívoco de analisar um processo a partir de processos futuros a ele relacionados (a problemática ilusão retrospectiva), interpreta-se que o ciclo de protestos de 2013 apresenta uma significativa vinculação com a destituição presidencial de $2016 \mathrm{em}$, pelo menos, dois aspectos. De um lado, o ciclo de protestos de 2013 produziu um abalo importante no apoio social ao governo da presidenta Dilma, em função do acirramento e da difusão de críticas progressistas e conservadoras, à esquerda e à direita. De outro lado, no ciclo de protestos de 2013 emerge pela primeira vez um ativismo extra-institucional conservador com importante capacidade de mobilização social. Se as grandes manifestações pró Impeachment de 2015 e 2016 não estavam predeterminadas em/por 2013, não se pode desconsiderar que atores,

dos atores nestas categorias faz parte da disputa política e, especialmente, que atores podem ser progressistas em relação a determinadas causas e conservadores em relação a outras. 
redes e recursos centrais para a produção daquelas manifestações foram gestados ou fortalecidos no/pelo ciclo de protestos de 2013.

\section{Movimentos, contramovimentos, atribuição de oportunidade e apropriação}

Partindo de uma tendência a conceber os movimentos sociais como uma forma de expressão política de segmentos dominados ou excluídos da política institucional (McAdam 1997), a literatura de movimentos sociais tradicionalmente privilegiou os atores e/ou as redes movimentalistas destes segmentos como seu objeto de análise. Neste sentido, tendeu a concentrar seu foco de interesse nos processos de formação, desenvolvimento, atuação, resultados e/ ou declínio de determinadas organizações de movimentos sociais, campanhas, protestos e/ou eventos de confronto envolvendo aqueles segmentos. Esta tendência, no entanto, tem sido objeto de crescentes questionamentos na literatura em virtude de duas limitações que ela coloca às análises dos processos de confronto político: de um lado, a perda da dimensão relacional dos processos abordados; de outro, a desconsideração dos processos de organização e mobilização dos atores e das redes opositores aos movimentos sociais.

Para confrontar estas limitações, autores têm defendido a necessidade de um deslocamento do foco analítico dos atores para as relações entre os atores que produzem os processos de confronto e, ao mesmo tempo, são produzidos em tais processos. Neste sentido, por exemplo, Klandermans (1992) critica a limitação do foco da literatura de movimentos sociais nas organizações de movimentos sociais e seus apoiadores. Para o autor, os movimentos sociais devem ser analisados como atores/redes situados em campos multi-organizacionais formados por uma diversidade de atores, sendo muitos deles opositores aos movimentos. Goldstone (2004), por sua vez, defende que a literatura de movimentos sociais deveria dirigir sua atenção para o que denomina de campos relacionais: as estruturas de relações constituídas pelos atores de movimentos sociais através de suas interações com instituições estatais, aliados, adversários, população em geral, entre outros. Ao proporem um deslocamento do foco de análise do movimento social para o confronto político, McAdam, Tarrow e Tilly (2001) e Tilly e Tarrow (2007) também expressam a necessidade de dar centralidade analítica para as relações entre atores e não apenas para determinados atores inseridos em tais relações.

Seguindo a perspectiva relacional constitutiva das propostas referidas acima, a análise desenvolvida neste artigo interpreta os conflitos subjacentes ao processo político que produz o ciclo de protestos de 2013 a partir de uma 
abordagem que direciona seu foco analítico às relações entre movimentos e contramovimentos sociais (Banaszak e Ondercin 2010, Meyer e Staggenborg 1996, Zald e Useem 1987). Tal abordagem não constitui uma novidade, mas é pouco mobilizada em pesquisas empíricas, particularmente no Brasil. Esta abordagem critica a concentração da literatura de movimentos sociais em movimentos particulares (ou, ainda, em organizações de movimentos sociais particulares) ou na relação entre os movimentos/organizações de movimentos e o Estado, desconsiderando a importância das relações entre movimentos sociais e contramovimentos. Em especial, desconsidera-se como a organização e atuação de movimentos sociais criam oportunidades, ameaças e condições para a constituição de contramovimentos. Contrapondo-se a esta limitação, Zald e Useem (1987: 247-248) argumentam que

movimentos de qualquer visibilidade e impacto criam as condições para a mobilização de contramovimentos. Ao advogar mudanças, atacar interesses estabelecidos, mobilizar símbolos e aumentar custos para outros, eles criam ofensas e oportunidades políticas para empreendedores organizacionais definirem objetivos e demandas de contramovimentos. Movimentos também tem um 'efeito demonstração' para contramovimentos políticos - mostrando que a ação coletiva pode produzir (ou resistir a) mudanças em aspectos particulares da sociedade.

Partindo deste argumento, interpreta-se que as conquistas obtidas por vários movimentos sociais progressistas durante os governos petistas em termos de políticas de reconhecimento e/ou redistribuição, mesmo que limitadas frente às demandas ou expectativas de tais movimentos, produziram mudanças sociais que foram interpretadas como ameaças por segmentos conservadores da sociedade brasileira. Para se oporem a estas ameaças e aos atores (movimentos, partidos e/ou governos) identificados como seus promotores, tais segmentos constituíram contramovimentos que passaram a se expressar publicamente a partir de meados dos anos $2000^{5}$. São atores destes contramovimentos que irão

5 Não será possível abordar neste artigo as relações entre movimentos e contramovimentos anteriores a 2013. No entanto, apenas para exemplificar, destaca-se que a introdução das políticas de ação afirmativa nas universidades públicas federais a partir de 2003, resultante da ação de ativistas e organizações de movimentos pela igualdade racial, teve como resposta a organização e ação política de contramovimentos formados por estudantes opositores à política de cotas. Em diversas universidades brasileiras, como na Universidade Federal do Rio Grande do Sul em 2009, estes contramovimentos conquistaram a direção de Diretórios Centrais de Estudantes (DCES) e atuaram ativamente na oposição àquela política. Neste ativismo estudantil conservador, como abordado adiante, serão formados diversos atores que 
identificar na conflitualidade da primeira fase do ciclo de protestos de 2013 uma oportunidade para sua intervenção e, ao mesmo tempo, apresentarão as condições para o aproveitamento de tal oportunidade, apropriando-se parcial e temporariamente do ciclo de protestos para seus objetivos.

Esta interpretação introduz duas alterações em argumentos recorrentes na literatura de movimentos sociais. De um lado, oportunidades foram tradicionalmente abordadas como resultantes de realinhamentos, fragilidades e/ou conflitos entre atores políticos dominantes, que assim aumentavam as possibilidades (ou, ao menos, as expectativas) de sucesso dos movimentos sociais desafiantes (Tarrow 2009). No caso do ciclo de protestos de 2013, ao contrário, o argumento é que conflitos produzidos por movimentos sociais foram interpretados por atores de contramovimentos conservadores como oportunidades para sua mobilização.

De outro lado, o mecanismo de apropriação foi utilizado pela literatura de movimentos sociais para analisar a utilização de organizações previamente existentes para a mobilização dos movimentos (a denominada "apropriação social" abordada por McAdam, Tarrow e Tilly 2001) ou para analisar a utilização de recursos de instituições para a organização e atuação dos movimentos (a denominada "apropriação institucional" abordada por Tarrow 2001). A particularidade do caso em foco é que não há uma apropriação de recursos ou de estruturas organizativas, mas sim de um repertório: o protesto. Os contramovimentos tendem a somar-se a manifestações organizadas pelos movimentos sociais em 2013, inserindo nas mesmas suas causas, símbolos e táticas.

Utiliza-se neste artigo o conceito de ciclo de protestos para identificar o processo conflitivo ocorrido no Brasil no ano de 2013. Segundo Tarrow (2009: 182), um ciclo de protestos pode ser definido

como uma fase de conflito acentuado que atravessa um sistema social: com uma rápida difusão da ação coletiva de setores mais mobilizados para outros menos mobilizados; com um ritmo rápido de inovação nas formas de confronto; com a criação de quadros interpretativos de ação coletiva, novos ou transformados; com uma combinação de participação

participarão ativamente na organização e direção das manifestações anti-Dilma em 2015 e 2016. 
organizada e não-organizada; e com sequências de fluxos intensificados de informação e de interação entre os desafiantes e as autoridades.

Ou seja, o objeto da análise não é um movimento social ou um conflito específico. Ao contrário, é um processo de difusão do confronto para diversos segmentos da sociedade, envolvendo atores e causas caracterizados, em maior ou menor grau, por significativa heterogeneidade.

O ciclo de protestos de 2013 é um processo que ainda demanda esforços de investigação mais aprofundados. As dificuldades de sua análise se originam, por um lado, exatamente nas suas importantes variações locais e temporais. A depender do ponto de vista geográfico ou temporal a partir do qual o processo é abordado, a caracterização do mesmo apresentará diferenças importantes. A generalização de análises realizadas em alguns locais/momentos, particularmente na cidade de São Paulo durante o mês de junho, produziu interpretações marcadas por significativas distorções no que se refere à caracterização e interpretação do processo nacional (Tavares, Roriz e Oliveira 2016).

Por outro lado, é preciso salientar que as interpretações sobre 2013 ainda são objeto de intensas disputas políticas no Brasil. A qualificação do ciclo de protestos de 2013 como uma sublevação do proletariado precarizado (Braga 2013, Antunes 2013), como a revolta de uma esquerda autonomista e anti-institucional (Ortellado 2013), como um levante popular (Moraes 2014) ou como a emergência da reação conservadora e, no limite, fascista (Marenco 2014) acaba sendo relacionada não apenas a esforços de compreensão do processo, mas à (des)legitimação de determinadas posições políticas.

A interpretação adotada neste artigo, ao utilizar o conceito de ciclo de protestos para apreender analiticamente o conjunto de manifestações contenciosas ocorrido em 2013, enfatiza o caráter heterogêneo deste processo. Desta forma, qualquer tentativa de impor um único sentido a tal processo se mostra necessariamente problemática. Ao contrário, como salientado acima, o ciclo de protestos de 2013 foi marcado por significativas diferenças locais e temporais. Tais diferenças, argumenta-se, resultaram de variações na presença e atuação de atores muito diversos (e, por vezes, em relações de conflito) que participaram na produção do ciclo de protestos $2013^{6}$. Assim, este pode assumir características muito distintas (progressista ou conservador, violento ou pacífico, construído por organizações de movimentos sociais ou mobilizado pela mídia ou redes sociais da Internet) a depender de quem, quando e onde se está analisando.

6 Interpretação similar pode ser encontrada em Alonso e Mische (2016). 
Seguindo o argumento da seção anterior, interpreta-se que é equivocado analisar o ciclo de protestos de 2013 de forma unificada. Neste sentido, a partir de suas características mais gerais (que podem ocultar importantes variações locais), propõe-se uma separação do ciclo em três fases distintas.

A primeira, que se inicia ainda em $2012 \mathrm{em}$ algumas poucas capitais do país e vai até o início de junho de 2013, é caracterizada por processos de contestação local ao aumento da tarifa do transporte público. Tais processos foram construídos por organizações políticas e coletivos progressistas (com destaque para atores identificados com o autonomismo e a crítica à política institucional), enfrentando forte repressão policial e a condenação midiática.

A primeira fase do ciclo de protestos de 2013 foi o primeiro grande processo de contestação social progressista desde a redemocratização que não teve no PT e nos movimentos sociais a ele articulados, seus agentes centrais (Nunes 2014: 45) ${ }^{7}$. Ao contrário, governos petistas de diferentes níveis (municipal, estadual e federal) se colocaram como alvo das demandas sociais e, em muitos casos, foram identificados como responsáveis pelos problemas sociais criticados pelos manifestantes.

As estruturas organizativas que construíram esta primeira fase apresentam importantes variações locais. O Movimento Passe Livre (MPL) em São Paulo, a Frente de Luta do Transporte Público em Goiânia, o Bloco de Lutas pelo Transporte Público em Porto Alegre, entre outros atores/coalizões que emergiram como organizadores dos primeiros protestos, não conformam nem integram uma organização nacional. Ao contrário, tendem a ser redes que apresentam grande diversidade entre si e, também, entre os atores que as compõem.

Outra característica desta fase é que as manifestações catalisaram a participação de vários campos de ativismo juvenil que não tinham no transporte público a sua causa central. Assim, observa-se nos protestos a mobilização de jovens, em grande parte universitários, vinculados a diversas causas, redes e organizações: coletivos autonomistas, feministas e antirracistas; diretórios acadêmicos; tendências estudantis de partidos de esquerda; setores de juventude de organizações de movimentos sociais populares; entre outros. Um ponto em comum entre esta diversidade de atores, além da defesa de causas

7 A não centralidade não significa ausência. Em Porto Alegre, por exemplo, ativistas da juventude do PT tiveram uma importante participação na construção das manifestações, integrando o Bloco de Lutas pelo Transporte Público. 
progressistas, era a crítica à atuação política institucional e o apoio ao uso de repertórios de confronto para a expressão de suas demandas (Silva 2016, Silva e Silva 2016).

Apesar da utilização intensa das redes sociais da Internet como instrumentos de informação, difusão e mobilização, observa-se nesta fase a presença de uma base organizativa que estrutura e coordena as ações públicas. No caso de Porto Alegre, por exemplo, as Assembleias do Bloco de Lutas eram momentos centrais de deliberação coletiva, observando-se um forte predomínio dos ativistas com vínculos organizativos na apresentação de propostas e na condução das discussões e decisões. Mesmo as iniciativas individualizadas de convocação para os protestos utilizavam os atos marcados e dirigidos pelo Bloco de Lutas como referência (Muhale 2014).

O êxito da mobilização de Porto Alegre na revogação do aumento da passagem, que ocorre no início do mês de abril, produziu um importante efeito ao mostrar a eficácia da ação contenciosa para a obtenção das demandas reivindicadas. Neste sentido, por exemplo, na manifestação realizada pelo MPL em São Paulo, em o6 de junho de 2013, uma faixa anunciava: "Vamos repetir Porto Alegre" (GaúchaZH 2013).

No entanto, como colocado anteriormente, esta primeira fase do ciclo de protestos de 2013 ficou limitada a algumas poucas cidades e, se o processo contestatório não apresentasse mudanças significativas, provavelmente seus impactos seriam bastante limitados. A segunda fase do ciclo de protestos, que se inicia a partir de meados de junho, é aquela que efetivamente se caracterizou como um processo nacional, apesar da profunda heterogeneidade de suas expressões locais ${ }^{8}$.

A segunda fase, entre os meses de junho e julho, é marcada pela difusão massiva dos protestos em escala nacional, a entrada em cena de novos atores e causas (com destaque para aqueles do campo conservador, que passam a disputar o sentido e a condução dos protestos), a diminuição da repressão policial e o apoio seletivo dos meios de comunicação.

A nacionalização não significou apenas a expansão geográfica, mas também a ampliação do público mobilizado para além das redes dos movimentos sociais progressistas. Segundo os dados sobre os manifestantes no protesto de 18 de junho em São Paulo (Folha de São Paulo 2013a), $71 \%$ estavam participando pela primeira vez de protestos, $84 \%$ não tinham preferência partidária e

8 O ápice dos protestos ocorreu no dia 20/06/2013, com manifestações em pelo menos 69 cidades e envolvendo em torno de um milhão e meio de participantes. Um dos vários levantamentos sobre os protestos de 2013 pode ser encontrado em: https://pt.wikipedia.org/wiki/ Cidades_participantes_dos_protestos_no_Brasil_em_2013 (Acesso em 7/12/2017). 
$85 \%$ haviam sido convocados através das redes sociais da Internet. Ou seja, a maioria dos indivíduos não tinha histórico de ativismo e estavam desconectados de redes organizativas.

Já a pesquisa sobre os participantes nos protestos de 20 de junho, realizada em sete capitais e em Brasília (G1 2013), informa que: $43 \%$ tinha curso superior completo e $49 \%$ havia concluído o ensino fundamental e/ou tinha curso superior incompleto; o Facebook havia sido a principal fonte de informações (62\%) e o principal mobilizador ( $77 \%$ ); $86 \%$ não eram vinculados a organizações sociais e $96 \%$ não eram filiados a partidos políticos. Novamente, o perfil predominante é de pessoas de alta escolaridade, desconectadas de organizações sociais e políticas, informadas e mobilizadas pelas redes sociais da Internet.

Além do público, há uma mudança nas causas defendidas nas manifestações que, paralelamente ao tema do transporte público (o qual, em muitos casos, praticamente desaparece), passam a incluir um amplo leque de reivindicações. Neste aspecto, destacam-se as demandas contra o governo federal e, particularmente, a centralidade que a corrupção assume como causa mobilizadora. No protesto realizado no dia 18 de junho em São Paulo, enquanto $56 \%$ indicavam o aumento da tarifa como motivação para protestar, a corrupção já aparecia em segundo lugar como motivação, apontada por $40 \%$ dos entrevistados (Folha de São Paulo 2013a). Nas cidades pesquisadas nos protestos de 20 de junho, enquanto a tarifa se colocava como a principal causa para $27,8 \%$ dos entrevistados, a corrupção aparecia em segundo lugar como a principal causa, com $24,2 \%$ (mas quando tomadas as três principais razões para protestar, a corrupção aparecia em primeiro lugar, com $49 \%$, enquanto a tarifa aparecia em segundo lugar, com 40,5\%) (G1 2013).

Por fim, a terceira fase, a partir do final de julho, é marcada por um declínio dos protestos, a saída dos setores conservadores das ruas e surgimento de novas demandas do campo progressista (como a oposição aos gastos e, especialmente, aos impactos sociais das obras da Copa do Mundo, que seria realizada em 2014).

Segundo a pesquisa realizada por Barbieri (2015) sobre as manifestações em Porto Alegre, a intensificação da repressão policial e o declínio do apoio social aos protestos teve um importante efeito desmobilizador neste momento, com o afastamento de vários indivíduos e organizações ${ }^{9}$. Já a pesquisa de Silva

9 Esta mudança na opinião pública pode ser observada nos seguintes dados: enquanto $89 \%$ dos entrevistados de São Paulo apoiavam os protestos no final de junho de 2013, este apoio havia caído para $52 \%$ em maio de 2014; enquanto 61\% avaliavam, em junho de 2013, que os protestos geravam mais benefícios do que prejuízos, esta avaliação cai para $25 \%$ em maio de 2014 . 
(2016), também em Porto Alegre, mostra que o refluxo do ativismo conservador nesta terceira fase está relacionado, entre outros fatores, à oposição às táticas "violentas" dos ativistas progressistas com quem compartilharam as ruas na fase anterior. Segundo um entrevistado que participou ativamente da mobilização conservadora em junho de 2013, "aconteceu muita coisa assim que fez as pessoas desestimularem, porque não se identificavam com essa forma de fazer manifestação né, que fez a coisa ir esfriando, né, esfriando e parou em 2013, que foi o vandalismo, foi o saque às lojas, as brigas, os tumultos, o confronto com a polícia" (Silva 2016:147).

Conforme a caracterização apresentada na seção anterior, a segunda fase do ciclo de protestos de 2013 não foi marcada apenas por uma mudança quantitativa, na escala do processo contencioso. Além do crescimento em termos de locais e pessoas envolvidos, observou-se também uma mudança qualitativa. Ou seja, argumenta-se que ocorreu uma mudança na configuração do processo contencioso em termos de seus atores, causas e conflitos constitutivos. Como se produziu esta mudança qualitativa? Como um processo de contestação se transformou em algo distinto em um período de poucos dias? Estas são questões fundamentais e, ao mesmo tempo, ainda nebulosas para os pesquisadores.

No entanto, é possível identificar e analisar alguns elementos que contribuem para compreender tal transformação. A argumentação desenvolvida nesta seção se distingue de grande parte da literatura sobre o ciclo de protestos de 2013, como Alonso e Mische (2016), que identifica na indignação com a repressão policial o mecanismo responsável pela difusão e nacionalização dos protestos. Sem desconsiderar esta indignação, destaca-se aqui a agência de atores que atuaram ativamente para produzir a mudança qualitativa observada nos protestos durante a segunda fase do ciclo $^{10}$.

O primeiro elemento a ser destacado é o protagonismo de organizações e ativistas conservadores. Conforme referido anteriormente, estes atores vinham atuando desde o primeiro governo Lula e, especialmente a partir de 2007, passaram a investir na construção de manifestações contra os

10 Discorda-se aqui, também, da interpretação de Domingues (2013: 67), quando este afirma que os setores liberais e conservadores se "apresentaram de maneira autônoma, mas sem que ninguém lhes dirigisse efetivamente, nem sequer os grandes meios de comunicação, que se mostraram bastante confusos e desorientados, como todo, frente a inesperadas mobilizações instantâneas e massivas". 
governantes petistas, tendo como principal alvo a "corrupção do PT" (Tatagiba, Trindade e Teixeira 2015). Ou seja, quando começa a ocorrer a primeira fase do ciclo de protestos de 2013, já havia uma infraestrutura organizativa atuante em diversos espaços sociais (mídia, redes sociais da Internet, mundo associativo das elites econômicas, partidos políticos conservadores, entre outros) com capacidade de rapidamente identificar e aproveitar as oportunidades trazidas pelos protestos.

Em sua pesquisa sobre a organização Estudantes pela Liberdade (EPL), por exemplo, Gobbi (2016) analisa um intenso processo organizativo e de mobilização dos atores liberais-conservadores, que já vinha ocorrendo previamente ao ciclo de protestos de 2013. E, em particular, o autor mostra como ativistas deste campo criam a organização Movimento Brasil Livre (MBL) em junho de 2013 precisamente para intervir no ciclo de protestos. Segundo um entrevistado de Gobbi (2016: 51), que tinha uma posição de direção no EPL, "Em 2013 estava havendo aquelas manifestações do Passe Livre, então a gente [EPL] criou uma outra organização [MBL] para participar disso". Mais adiante, o autor afirma:

A primeira aparição digital do Movimento Brasil Livre data de 17 de junho de 2013, quando a página do Movimento foi criada no Facebook. Conforme informa o Entrevistado 3, a ideia para criação do movimento partiu de Juliano Torres, durante as manifestações de junho de 2013, que enxergou naquele momento uma oportunidade para criar um movimento pautado pelas ideias libertárias no Brasil.

GOBBI, 2016: 67

Outro exemplo da presença e atuação destes atores do campo conservador pode ser observado na rápida difusão de grupos identificados com a denominação "Vem pra Rua" durante o ciclo de protestos de 2013. A ação destes grupos na organização da intervenção conservadora nos protestos em Porto Alegre pode ser observada no depoimento de um entrevistado de Silva (2016):

comecei a procurar grupos que organizavam, comecei a ir pra Internet e a pesquisar grupos. E achei vários, né. E tentei contato com os organizadores. E um dos únicos [que respondeu] foi o Vem pra Rua ou algo assim. E aí a gente começou a conversar. Eu tinha algumas ideias de como organizar melhor a manifestação, de como dar uma segurança melhor pras pessoas. E aí o pessoal me convidou pra ajudar na manifestação. E aí a gente começou e teve reuniões e conheci pessoalmente eles e tal. [...] nós tentávamos dar um pouco de organização. Então, horário, o itinerário, 
por quais ruas nós vamos percorrer, os dizeres dos cartazes, o que a gente vai pedir, né? Porque a maioria das pessoas foi pra rua, mas sem muito conhecimento assim do que pedir. Sabia que a coisa tava ruim, tava péssima, né. E não era só por causa da passagem, dos vinte centavos lá da passagem. Não era. Era contra a corrupção. [...] Aí a gente começou a criar pautas pra manifestação: 'bom, nessa manifestação a gente vai pedir não à $\mathrm{PEC}_{37}$, vamos pedir não à $\mathrm{PEC}_{37}$, fora corrupção'.

O segundo elemento para compreender as transformações entre a primeira e a segunda fase do ciclo de protestos é a atuação da mídia corporativa em 2013. Quando se observa a cobertura do ciclo de protestos de 2013, identifica-se uma mudança significativa na forma de enquadramento dos protestos ao longo do tempo. Na primeira fase do ciclo, a cobertura da mídia corporativa reproduz o padrão histórico de enquadramento condenatório dos protestos: os manifestantes são caracterizados negativamente (sendo recorrente adjetivá-los como vândalos); as causas dos protestos tendem a ser desqualificadas, secundarizadas ou ocultadas; a ação policial repressiva sempre é justificada e nunca interpretada como violenta; e os repertórios utilizados pelos manifestantes são criticados por causarem problemas nos locais de ocorrência dos protestos e danos ao patrimônio público e/ou privado (Fernandes 2016).

Na segunda fase, no entanto, observa-se uma significativa e rápida reorientação do enquadramento midiático. Esta reorientação pode ser observada primeiramente na cidade de Porto Alegre. Segundo pesquisa de Fernandes (2016), o jornal Zero Hora, principal jornal do estado do Rio Grande do Sul, vinha enquadrando os protestos dentro do tradicional padrão condenatório até o início de abril, quando o aumento da tarifa é revogado. A partir deste momento, há uma mudança na linha editorial do jornal (assumida publicamente pelo jornal através da publicação de uma carta da editora-chefe no dia 07 de abril) no que se refere ao enquadramento dos protestos: 0 ato de protesto deixa de ser criminalizado e/ou desqualificado (que se expressa no abandono do uso do termo "baderna", recorrente na cobertura realizada até então), sendo criticados apenas os repertórios que utilizam violência; o manifestante também deixa de ser tratado negativamente, introduzindo-se uma diferenciação no público dos protestos entre a grande maioria dos manifestantes (pacífica e legítima) e a minoria de vândalos (violentos e ilegítimos). Este novo enquadramento será reforçado a partir de junho, quando novos atores e causas passam a estar presentes nos protestos.

Uma mudança similar pode ser identificada nos meios de comunicação do centro do país. O jornal Folha de São Paulo, um dos mais importantes do país, mantinha a cobertura crítica às manifestações do MPL até o ato do dia 
13 de junho. Neste dia, ocorre uma repressão policial extremamente violenta ao protesto, que fere inclusive uma repórter do jornal. A partir do dia seguinte, a Folha altera sua cobertura, adotando um padrão bastante similar ao da Zero Hora ${ }^{11}$.

A mesma mudança foi observada na cobertura da Rede Globo, a principal do país. No Jornal da Globo do dia 12 de junho, por exemplo, o comentarista Arnaldo Jabor compara os manifestantes paulistas a uma organização criminosa, desqualificando os participantes, suas demandas e seus repertórios de ação. Cinco dias depois, o mesmo comentarista, no mesmo jornal televiso, faz uma autocrítica e passa a celebrar os manifestantes e sua mobilização.

Com a mudança no enquadramento, a mídia passou não apenas a disputar as interpretações sobre os protestos, mas também a construção dos mesmos. A transmissão em tempo real das manifestações, realizada especialmente pela Rede Globo, constituiu-se em um importante mecanismo de difusão nacional dos protestos. No dia 20 de junho, ápice da ocorrência dos eventos de protesto, a Rede Globo concentrou suas transmissões ao longo do dia na cobertura dos protestos. Até mesmo as novelas da emissora, muito populares no Brasil, deixaram de ser exibidas neste dia para darem lugar à exibição das manifestações que ocorriam em todo o país.

Alegitimação dos protestos pela cobertura midiática teve repercussões sobre a legitimidade deste repertório de confronto na opinião pública. Enquanto em 13 de junho 55\% dos entrevistados em São Paulo apoiavam as manifestações, este número sobe para $77 \%$ em 18 de junho (Folha de São Paulo 2013b). Em $27-28$ de junho, a aprovação aos protestos sobe para $89 \%$ dos entrevistados (Folha de São Paulo, 2014). Esta aprovação generalizada dos protestos, sem dúvida, foi um dos elementos que contribuíram para a mobilização de novos atores na segunda fase do ciclo de protestos de 2013, entre os quais os setores conservadores ${ }^{12}$. Em entrevistas com participantes dos protestos de junho em Porto Alegre, por exemplo, observou-se a mobilização de pessoas que tradicionalmente não apenas não participavam de protestos, mas que tinham até então uma posição de rejeição a este tipo de repertório de ação.

Além da legitimação, a mídia incidiu na construção dos protestos ao enfatizar a eficácia dos mesmos para a obtenção das demandas da sociedade. Tal

11 Para uma análise detalhada da cobertura da Folha de São Paulo aos protestos de 2013 ver Müller (2015).

12 Concorda-se, no entanto, com Singer (2013) que não se pode identificar todos os atores que entraram na segunda fase do ciclo de protestos como conservadores, nem tratar a pauta da corrupção como um tema exclusivo do conservadorismo. 
enquadramento se destaca na análise de Fernandes (2016) sobre a cobertura do Jornal Zero Hora: mostrando conquistas como a revogação do aumento da passagem em várias cidades e a não aprovação da PEC 37 pelo Congresso Nacional, o jornal afirmava que os protestos ensinaram "a lição de que o poder público cede ao ser pressionado pela massa" (Fernandes 2016: 213).

Por fim, o terceiro elemento para explicar a mudança qualitativa entre a primeira e a segunda fase do ciclo de protestos de 2013 foi a capacidade e habilidade no aproveitamento, pelos atores conservadores, das novas oportunidades de comunicação, informação e mobilização disponibilizada pela Internet associada à telefonia móvel ${ }^{13}$. Na medida em que as organizações conservadoras constituídas nos anos anteriores, em sua quase totalidade, não eram organizações de massa, as redes sociais da Internet (em especial, o Facebook) se tornaram o seu principal instrumento e espaço de difusão de frames, de ataque aos adversários, de convocação para as ações públicas e de acesso a novos públicos.

Mas o alcance e efeito da ação política dos conservadores na Internet foi potencializado significativamente pela sua vinculação direta com a atuação midiática ${ }^{14}$. Observa-se no ciclo de protestos de 2013 um processo de retroalimentação entre os conteúdos publicados nas redes sociais conservadoras e os conteúdos da mídia. Jornalistas, comentaristas, intelectuais e celebridades midiáticas conservadoras passaram a ser reproduzidos intensamente nas redes sociais, assim como ativistas conservadores atuantes nas redes sociais passaram a ter suas ações e discursos reproduzidos e difundidos na mídia. Um claro exemplo desta articulação é o fato de Kim Kataguiri, do M BL, e Rogério Chequer, do Vem pra Rua, tornarem-se posteriormente colunistas do jornal Folha de São Paulo.

\footnotetext{
13 A análise aqui desenvolvida diverge da interpretação de Castells (2015) sobre o ciclo de protestos de 2013 no Brasil e, mais especificamente, as implicações do uso das redes sociais da Internet neste processo.

14 Em um país radicalmente desigual como o Brasil, o acesso à Internet e à telefonia móvel também é marcado pela desigualdade. Segundo dados da Secretaria de Comunicação Social da Presidência da República (Brasil 2014), 53\% dos brasileiros não acessavam a Internet em 2013, sendo a exclusão maior entre os mais pobres ( $78 \%$ entre aqueles que recebiam até 1 salário mínimo) e menos escolarizados ( $91 \%$ entre aqueles que tinham 4 anos ou menos de escolarização). Assim, a televisão, que atingia $97 \%$ dos brasileiros em 2013, se colocava como um instrumento fundamental para a difusão do frame conservador para o conjunto da população.
} 

dos protestos

Um dos principais enigmas do ciclo de protestos de 2013 é compreender como foi possível que um processo de confronto passasse pela mudança qualitativa observada ao ser parcialmente apropriado por atores que não estavam presentes no seu início. Uma parte da resposta se encontra na agência de atores conservadores abordada na seção anterior. No entanto, tal agência tenderia a fracassar caso houvesse uma incompatibilidade total entre os iniciadores do ciclo de protestos e aqueles que a ele aderem posteriormente, transformando-o.

Dois elementos parecem ter sido fundamentais na criação das condições de compatibilidade, parcial e temporária, entre movimentos progressistas e contramovimentos conservadores naquele momento. $\mathrm{O}$ primeiro elemento a ser destacado é o compartilhamento, por motivos distintos, de um posicionamento crítico ao PT e seus governos. Conforme as análises realizadas sobre o Bloco de Lutas em Porto Alegre (Muhale 2014, Silva 2016) ou o MPL em São Paulo (Alonso e Mische 2016, Ortellado 2013), a rede ativista que constrói a primeira fase do ciclo de protestos de 2013 é marcada por uma forte atuação de militantes de coletivos anarquistas/autonomistas e de partidos de esquerda constituídos a partir de cisões internas do PT (PSOL e PSTU, principalmente). Tais grupos políticos tendiam a apresentar publicamente fortes críticas aos limites da atuação dos governos petistas em termos de produção de transformações radicais nas relações de desigualdade que caracterizam a sociedade brasileira. O chamado "pacto de classes" do petismo era interpretado como uma deslealdade e um obstáculo àquelas transformações. As acusações de corrupção colocavam o PT como mais um partido reprodutor da "velha política" das elites brasileiras. As posições ambivalentes de governantes do PT, como o governador do Rio Grande do Sul Tarso Genro e o prefeito de São Paulo Fernando Haddad, sobre a ação repressiva das polícias nos eventos de protesto eram percebidas como traição aos movimentos sociais. Um exemplo ilustrativo deste conflito com o PT é a expulsão dos militantes petistas do Bloco de Lutas em Porto Alegre, que ocorre na terceira fase do ciclo de protestos.

Este enquadramento crítico do PT e de seus governos por parte de importantes segmentos dos atores mobilizados na primeira fase do ciclo de protestos possibilitou um alinhamento, parcial e temporário, com o enquadramento antipetista que fundamentava os discursos dos contramovimentos conservadores que ingressam na segunda fase. Apesar das motivações e intencionalidades bastante distintas, a crítica ao PT ofereceu um alvo comum a uma parcela significativa dos atores heterogêneos que compartilhavam as ruas nos meses de junho e julho de 2013 . 
O segundo elemento que atuou na criação de condições de compatibilidade entre atores tão heterogêneos refere-se à crítica à participação política institucional e à defesa da ação confrontacional extra-institucional como mecanismo fundamental de atuação política. Um elemento central da crítica de militantes progressistas ao PT era a interpretação que o partido havia perdido sua "combatividade" e, ainda, cooptado e desmobilizado os movimentos sociais ao inseri-los em processos e espaços políticos institucionais. Tais processos e espaços produziriam inescapavelmente uma fragilização das lutas sociais e, por isto, deveriam ser substituídos por uma atuação centrada na "ação direta".

Esta crítica à política institucional encontrou possibilidades de alinhamento com a desconfiança generalizada nas instituições e nos atores políticos que caracteriza a opinião pública brasileira e, também, com o componente antiestatal que integra a ideologia liberal-conservadora predominante entre os contramovimentos. Assim, juntamente com as críticas ao $\mathrm{PT}$, as críticas à política e ao Estado possibilitaram, durante um breve período, ocultar as profundas diferenças entre "libertários" e libertarians presentes e atuantes nas mesmas manifestações durante a segunda fase do ciclo de protestos de 2013.

\section{$7 \quad$ Conclusões}

A argumentação desenvolvida neste artigo buscou responder às seguintes questões: Como caracterizar o ciclo de protesto de 2013? Quais são seus principais atores? Como foram produzidas as mudanças qualitativas observadas entre as diferentes fases do ciclo?

A análise nos apresentou um processo dinâmico, iniciado por atores identificados com causas progressistas, mas parcialmente apropriado e transformado por atores conservadores durante a segunda fase. Tais atores conservadores foram capazes de identificar e aproveitar oportunidades constituídas pela ação confrontacional de atores que, em princípio, seriam seus adversários. $\mathrm{O}$ compartilhamento de críticas aos governos petistas, à política institucional e ao Estado parecem ser os fatores que criaram as condições de possibilidade desta improvável convergência, temporária e parcial, entre atores tão heterogêneos (e, de fato, em conflito).

Tal heterogeneidade produziu um processo que resiste a qualquer tentativa de interpretação homogeneizante. Assim, as diversas interpretações concorrentes apresentadas sinteticamente no início deste artigo não devem ser vistas como sendo necessariamente equivocadas. Ao contrário, parece mais adequado tratá-las como apreensões parciais de um processo que tem como características constitutivas a diversidade, a ambiguidade e, no limite, a contradição. 
São estas características que possibilitam que analistas relacionem o ciclo de protestos de 2013 a processos posteriores absolutamente distintos como, por exemplo, as manifestações pró impeachment de 2015 e 2016, as ocupações de escolas de 2015 em São Paulo, as ocupações de escolas e universidades em vários estados brasileiros em 2016, entre outros. De fato, parte dos atores, causas, enquadramentos e/ou repertórios presentes nestes processos posteriores também estavam presentes no ciclo de protestos de 2013. No entanto, contrapondo-se ao risco da ilusão retrospectiva, é um equívoco afirmar que tais processos posteriores já estavam predeterminados pelo que ocorreu em 2013. Se é correto estabelecer relações entre estes processos, certamente tais relações não podem ser de causalidade linear.

Argumentar que houve uma convergência, parcial e temporária, de movimentos progressistas e contramovimentos conservadores na segunda etapa do ciclo de protestos de 2013 não significa "culpar" os atores por este fato e seus desdobramentos. Um dos mais interessantes aspectos da abordagem centrada nas relações entre movimentos e contramovimentos é que ela abre um importante espaço analítico para interdependências, efeitos não intencionais e contingências que escapam a muitas abordagens e que são fundamentais para compreender a complexidade dos processos de confronto político.

Por fim, é importante destacar que a convergência observada na segunda fase do ciclo de protestos de 2013 foi sustentável por um período muito curto de tempo. A partir de então, observa-se uma clara demarcação e confrontação dos campos progressista e conservador. O improvável não tornou a ocorrer e, de fato, parece quase impensável que tenha ocorrido quando observamos o atual contexto de polarização política do país. Mas entender como foi possível sua ocorrência é importante não apenas para a explicação de um importante processo como foi o ciclo de protestos de 2013, mas também para a compreensão (e, para os atores comprometidos com a defesa da democracia, o enfrentamento) de um tipo de confronto político que atualmente está conduzindo o Brasil a um processo desdemocratização.

\section{Referências bibliográficas}

Alonso, A. \& Mische, A. 2016, "Changing Repertoires and Partisan Ambivalence in the New Brazilian Protests”, Bulletin of Latin American Research, 36 (2): 144-159.

Antunes, R. 2013, "As rebeliões de junho de 2013", osal Observatorio Social de América Latina, XIV (34): 37-49.

Banaszak, L. A. \& Ondercin, H. 2010, Explaining Movement and Countermovement Events in the Contemporary U.S. Women's Movement, Paper presented at the American Political Science Association Meeting. 
Barbieri, A. O. 2015, Do FIFA go home ao "Fora Dilma": uma etnografia dos protestos de rua em Porto Alegre (2013-2015), Trabalho de Conclusão em Ciências Sociais, Porto Alegre, Universidade Federal do Rio Grande do Sul.

Braga, R. 2013, "As jornadas de junho no Brasil: Crônica de um mês inesquecível", OSAL Observatorio Social de América Latina, XIV (34): 51-61.

Brasil 2014, Pesquisa brasileira de mídia 2014: hábitos de consumo de mídia pela população brasileira, Brasília, Secom.

Castells, M. 2015, Networks of outrage and hope: social movements in the Internet age, 2nd Edition, Cambridge, Polity Press.

Domingues, J. M. 2013, “Las movilizaciones de junio de 2013: ¿Explosión fugaz o novísima historia de Brasil?", OSAL Observatorio Social de América Latina, XIV (34): 63-73.

Fernandes, E. G. 2016, Campo de batalha jornalística: os enquadramentos construídos por Zero Hora, Diário Gaúcho e Sul21 na luta pela (i)legitimidade do ciclo de manifestações de 2013, em Porto Alegre/RS. Dissertação de mestrado em sociologia, Universidade Federal do Rio Grande do Sul.

Goldstone, J. A. 2004, "More social movements or fewer? Beyond political opportunity structures to relational fields", Theory and Society, 33: 333-365.

Gobbi, D. 2016, Identidade em ambiente virtual: uma análise da rede Estudantes pela Liberdade, Dissertação de mestrado em ciência política, Universidade de Brasília.

Klandermans, B. 1992, "The social construction of protest and multiorganizational fields", in A. Morris \& C. M. Mueller eds, Frontiers in social movement theory. Yale, Yale University: 77-103.

Marenco, A. 2014, "As duas caudas de Gauss: minorias, protestos e representação política", in A. D. Cattani ed., \#protestos: análises das ciências sociais, Porto Alegre, Tomo: 31-40.

McAdam, D. 1997, “The Political Process Model”, in S. Buechler \& K. Cylke Jr. eds, Social movements: perspectives and issues. Mountain View, Mayfield: 172-192.

McAdam, D., Tarrow, S. \& Tilly, C. 2001, Dynamics of contention, Cambridge, Cambridge University Press.

Meyer, D. \& Staggenborg, S. 1996, "Movements, Countermouvements, and the Structure of Political Opportunity”, American Journal of Sociology, 101 (6): 1628-1660.

Moraes, W. dos S. de 2014, "A convergência analítica dos herdeiros de Kautsky e Nozick: crítica às interpretações da direita e da esquerda estatista sobre o Levante de 2013 no Brasil", Em Debate, 11: 90-113.

Muhale, M. 2014, Lutar, criar poder popular: uma perspectiva etnográfica do Bloco de lutas pelo transporte público em Porto Alegre/RS, Dissertação de mestrado em antropologia, Porto Alegre, Universidade Federal do Rio Grande do Sul.

Müller, I. D. 2015, Enquadramento e cobertura do Jornal Folha de São Paulo acerca das manifestações sociais de junho de 2013, dissertação de mestrado em Diversidade Cultural e Inclusão Social, FEEvALE. 
Nunes, R. 2014, "Generación, acontecimiento, perspectiva - Pensar el cambio a partir de Brasil", Nueva Sociedad, 251: 42-54.

Ortellado, P. 2013, "Reflections on the Free Fare Movement and other 'new social movement", Mediações, 18 (2): 110-117.

Silva, C. F. da 2016, Inovação nos Repertórios de Contestação: O confronto em torno do transporte público em Porto Alegre, Dissertação de mestrado em sociologia, Universidade Federal do Rio Grande do Sul.

Silva, C. F. da \& Silva, M. K. 2016, “'Se a passagem não baixar, a cidade vai parar': transformações nas manifestações públicas de demandas relacionadas ao transporte coletivo na cidade de Porto Alegre, 1970-2013", in V. Marx ed., Participação, conflitos e intervenções urbanas: contribuições ao Habitat III, Porto Alegre, Editora da UFRGS: 156-177.

Singer, A. 2013, "Brasil, Junho de 2013 - Classes e ideologias cruzadas", Novos Estudos, 97: $23-40$.

Tarrow, S. 2001, «Transnational politics: contention and institutions in international politics », Annual Review of Political Science, 4: 1-20.

Tarrow, S. 2009, Poder em movimento:movimentos sociais e confronto político, Petrópolis, Vozes.

Tatagiba, L., Trindade, T., Teixeira, A. C. C. 2015, "Protestos à direita no Brasil (20072015)", in S. Velasco e Cruz; A. Kaysel; G. Codas, Direita, volver! - o retorno da direita e o ciclo político brasileiro, São Paulo, Fundação Perseu Abramo: 197-212.

Tavares, F. M. M., Roriz, J. H. R. \& Oliveira, I. C. de 2016, "As jornadas de maio em Goiânia: para além de uma visão sudestecêntrica do junho brasileiro em 2013", Opinião Pública, 22 (1): 140-166.

Tilly, C. \& Tarrow, S. 2007, Contentious politics, Boulder, Paradigm Publishers.

Zald, M. N. \& Useem, B. 1987, "Movement and countermovement interaction: mobilization, tactics, and state involvement", in M. N. Zald \& J. D. McCarthy eds, Social movements in an organizational society, New Brunswick, Transaction: 247-271.

\section{Artigos de imprensa}

Folha de São Paulo 2014, "Para 73\%, protestos geram mais prejuízos do que benefícios", Folha de São Paulo, consultado em 7/06/2018, http://www1.folha.uol.com.br/poder/ 2014/05/1458078-para-73-protestos-geram-mais-prejuizos-do-que-beneficios.shtml

Folha de São Paulo 2013a, "Em protesto de SP, maioria não tem partido, diz Datafolha", Folha de São Paulo, consultado em 7/06/2018, http://www1.folha.uol.com.br/ cotidiano/2013/o6/1296886-em-protesto-de-sp-maioria-nao-tem-partido-dizdatafolha.shtml

Folha de São Paulo 2013b "Cresce apoio a protestos contra a tarifa de ônibus entre paulistanos”, Folha de São Paulo, consultado em 7/o6/2018, http://datafolha.folha.uol 
.com.br/opiniaopublica/2013/06/1297619-cresce-apoio-a-protestos-contra-a-tarifade-onibus-entre-paulistanos.shtml

GaúchaZH 2013, "Porto Alegre inspira outras capitais em protestos contra aumento das passagens de ônibus", consultado em 7/06/2018, https://gauchazh .clicrbs.com.br/geral/noticia/2013/o6/porto-alegre-inspira-outras-capitais-emprotestos-contra-aumento-das-passagens-de-onibus-4163129.html

G1 2013a, "Veja pesquisa completa do Ibope sobre os manifestantes", Globo, consultado em 7/o6/2018, http://g1.globo.com/brasil/noticia/2013/o6/veja-integra-da-pesquisado-ibope-sobre-os-manifestantes.html

\section{Remerciements}

Agradeço aos comentários críticos de dois pareceristas anônimos que oportunizaram uma qualificação substantiva da versão anterior deste artigo. 